\title{
Persuasive Political Power Employed by Premier Imran Khan to Deform Identity: A Political Discourse Analysis
}

\author{
Zafar Iqbal \\ MPhil Scholar \\ Department of English \\ Minhaj University Lahore, Pakistan \\ Iqra Khan \\ BS English \\ Department of English \\ NCBA\&E, Lahore, Pakistan (Multan Campus)
}

\author{
Khurram Shahzad \\ MPhil Scholar \\ Department of English \\ Minhaj University Lahore, Pakistan \\ Talha Aslam (Corresponding Author) \\ School of Business Management \\ Bahria University, Islamabad, Pakistan
}

Received: August 28, 2020 Accepted: November 23, 2020 Published: November 29, 2020 doi:10.5296/jsel.v9i1.18005 URL: https://doi.org/10.5296/jsel.v9i1.18005

\begin{abstract}
The researchers investigate Pakistani Premier Imran Khan's (IK) speech in which he called Bilawal Bhutto Zardari - Sahiba. Similarly, the leaders strongly need to convince their supporters when they deliver speeches on public platforms. However, utilizing the
\end{abstract}


persuasive political power, the Premier (IK) propagated identity to promote the specific ideology to gain political benefits. The present research employs Political Discourse Analysis (PDA), to understand the social and political persuasive style employed by the premiere. The researchers have analyzed the data employing a qualitative approach. There are reliable findings to suggest that IK has successfully used stable vocabulary (taboo) to persuade the specific supporters, convincing them to deform the identity of Bilawal Bhutto. Later, the Premier faced considerable criticism from the opposition. However, for the time being, he successfully dominated through sociological and persuasive power sourcing the meaning-making structures of power. Hence, the politicians often convince their supporters/followers to utilize political-strategic tools and to remain in their political procession against their opponents.

Keywords: Political discourse; identity; political propagation; persuasive political power

\section{Introduction}

From a linguistic perspective, identity is often constructed and performed as a 'knowing' of a 'being,' yet, sometimes, it is misinterpreted at the level of language and discourse. Baxter (2016) argues that "in the context of language and identity, individuals have continued to make sense of conflicting 'ways of knowing' and, hence, competing 'ways of being"' (p. 36 as cited in Sheffield, 2013). Bourdieu (1991) argues that the language of influential people leaves an impact on the minds of the audience (Sheffield, 2013). For instance, any social power remains in the hands of the political elite, and the language of the powerful is considered the dominant language of the society; hence, media gives more power to this political language. Moreover, this power is not only restricted to the language, yet it also influences the political, social, and cultural power structure of the society (van Dijk, 1995, p. 9; Baig, et al., 2020).

The current research on political language and identity clarifies that how individuals construct or co-construct the identities of 'others' and determine their socio-political roles through the language (Akhtar et. al., 2020). For instance, Prime Minister Imran Khan (IK) of Pakistan utilizes the word 'Sahiba' (Sahiba' is often utilized for a lady for respect in the Urdu language, yet here for a man ironically) (see Appendix I for details) for the chairman of Pakistan People's Party, Bilawal Bhutto Zardari ${ }^{1}$, and abruptly this issue becomes a hotly debated topic amongst the people especially amongst the women. Women argue that how could a PM directly or indirectly sabotage a social or political identity of women showing a male with a female character ('Sahiba'). In the context of language and identity, females think that men by force often position them. For instance, Hatch (1997) argues that feminists understand and recognize it as they are the under-exercised force. Moreover, he suggests that the feminists recognize a new dimension of power stretched between two poles of action: action that is produced as the result of pressure from those in positions of authority and movement that is undertaken through one's authority" (p. 292 as cited in

\footnotetext{
${ }^{1}$ a Pakistani politician and the current chairman of the Pakistan Peoples Party.
} 
Sheffield, 2013). Hence, in the present case, women think that they are deliberately associated with weakness (See appendix 1 for details). However, many of the male community also argue that political language should not be utilized to propagate sexism or feminism to defame someone.

However, the present research does not fall into the field of feminism. So, the current research primarily focuses on the conscious utilization of the persuasive power employed by the Premier IK through language to propagate the identity of Bilawal Bhutto.

\section{Theoretical Framework}

\subsection{Socio-Political Discourse Analysis}

Political Discourse can be counted as a prerequisite aspect that supports in building implied and accurate meanings in the text (van Dijk, 2006; 2005; 1997b; 1998) that is under the target, especially in a context that is social and political based (van Dijk, 2018). Although it describes the social practices, relations based on power, and abstract based considerations, furthermore, it is a way of communication in a speech by using powerful and persuasive words (discourse) or composed structure (written form) (Iqbal et al., 2020; Baig et al., 2019). A Language that is brought into utilization, having the final target of communication with other people in the form of a written text or with the usage of speech sounds to transmit ideas, feelings, and emotions, is called discourse (Sharififar \& Rahimi, 2015). Conversation can be analyzed or observed in different manners with different endings when it is set, translated, and depicted, and even it needs to get clarified in a sense that in which way and why it shows or perform different functions (Rogers \& Schaenen, 2014). Discourse is considered an integral portrayal of the language concerned with actual practice possessing a specific approach, and it intends to deal with each type of person's intellectual ability (Iqbal et al., 2020). On the other hand, discourse analysis is a type of technical form possessing objectivity considering the material of discourse or any framework of basic necessity, and it deals with any way of communication to study the text in its context (Sibtain et al., 2020; Sharififar \& Rahimi, 2015). Kirvalidze \& Samnidze (2016) argue that political discourse could be divided into; political based background, socially constructed ideology, the effects known as psychological, and the individual's interpretation that can be revealed through the analysis that consists of political discourse (Aazam et al., 2019). The text can be divided into three undividable parts, i.e., used language, interactional words or sentences, and communication (van Dijk, 1997b; 2018). Furthermore, in recent times, the process of political discourse analysis is an interdisciplinary approach functioning at both levels, whether it is at the microscale or macro scale formed at the social and linguistic levels. Political Discourse Analysis bases, sometimes, on the level of education which apprehends particular doctrines, personalities, issues(political) related to legislation, philosophical ideas, and some other things having identification with it (Wodak, 2011; Dunmire, 2012; Kervalidze \& Samnidize, 2016). Furthermore, according to Kirvalidze \& Samnidze (2016), Political Discourse Analysis can be merged with different types of analyses such as sciences concerning psychology that values philosophy. That is why it is converted into the most utilized 
technique in the field of today's linguistics. It additionally unhides the systems of belief and relations of power, mostly found in political discourse. Additionally, PDA is a combination of supposition recognized with human science on a small scale, society, and power (van Dijk, 2001; Kirvalidze \& Samnidze, 2016; Sibtain et al., 2020; Iqbal et al., 2020). It is a typical method for clarification during the investigation of the discourse. There are a few critics who describe that there is not any method that might exist for PDA or to gather informative elements through PDA (Iqbal et al., 2020). Instead of this, it is a raw material to analyze content adopting an exemplary setting. The necessary task of PDA is to show the link of language, philosophical values, society, power, and other aspects (ibid). Xie (2018) suggests that PDA is a source for conducting speech discourse that appeared to be continuously well-famed and get more thoughtful things about individuals. To some extent, in the present age, to administer the discourse study in English speeches has become a big trend since the English language has a remarkable effect on the world. So, the individuals in politics, tend to be influential and persuasive in their speeches to get support in politics by touching the emotions of the masses. (Fischer \& Gottweis, 2012).

Sarfo \& Krampa (2013) comment that specific meanings can be understood when linguistic and persuasive devices are used in a socially described context. The researchers, scholars, as well as linguists, have also given considerable attention to the speeches of the day. These studies have highlighted problems concerning race, cast and identity, the transmission of culture, and other remarkable issues related to politics. Except for that, some of the studies were put in conduct at semantic, pragmatic, lexicon-grammar, and stylistic levels.

However, the researchers of recent times analyze the oral text employing PDA within linguistic and persuasive strategies IK uses in his speech to defame the real identity in social perspectives. For instance, Hassan (2018) argues that investigation in the qualitative aspect, applying the frameworks of CDA that should be conceptual, makes the spectators and researchers able to know the covert meaning of the given text at the initial stage through its concern with political and social context.

\subsection{Language, Identity and Politics}

Bourdieu (1991) argues that language is a social phenomenon that often exercises symbolic power, which is not genetic, yet, it is a social construction which is evolved through a process of generative development, which usually works on historical events. Language cannot be understood without sociological language interaction, which is required to realize/apprehend it by making sense. The essential understanding of grammar, sociology, and psychology of language is crucial and foundational elements that enhance human learning (Schwandt \& Marquardt, 2000 as cited in Sheffield, 2013). Baxter (2016) argues that our identity or 'subjectivity' is performed and constructed, positioning our sense of self, through or into language; accordingly, the poststructuralist thinkers (p. 36). According to Ferdinand de Saussure (1974), a structuralist linguist, language often constitutes a new social reality for individuals rather than the reflection of already given social reality. Language does not clarify the 'meaning,' yet it is produced within language (as cited in Baxter, 2016, p. 36). So, if an individual acquires a language that is already existed or 
constructed, he/she also learns the already existed or constructed meaning of language as a subject through an already-existing social contract like all other language users. Thus, as fixed-meaning, the identity of an individual would also be shaped through this pre-existing 'structuralist' language. So, if we consider language as a being that is often seen in flux, then 'identity' also changes itself accordingly. For instance, according to Erikson (1950), identity is, hence, an ongoing process that changes itself through an accumulative process throughout the life of a human. Henceforth, the identity would modify itself through the influence of shared-minded surroundings of individuals, as Hoare (2012) points out that youth announce their solidarity via a shared language and dress to conform to like-minded peers. Such conformity helps them overcome what, to Erikson, was an excessive self-awareness (p. 8 as cited in Sheffield, 2013). So, if identity is not considered as an evolution process, they would end the process of becoming itself (Erikson \& Newton, 1973, p. 109 as cited in Sheffield, 2013). The theory of the identity of Erickson (1950) could be liked to foundational 'symbolic interactionism' (see Mead, 1934 for details), which elaborates that identity gradually forms itself within language interactions that individuals acquire from their relationship to the external environment. Hoare (2012) appreciates the theory of the identity of Erikson and argues that:

"[he]developed a distaste for his concept of identity because it was so frequently misused. He held that identity development is not at an "achievement" or an unalterable accomplishment. He was concerned that specific dimensions of identity had been systematically excluded. To Erikson, three essential aspects-the unconscious, negatives, and society-were studiously ignored." (p.1 as cited in Sheffield, 2013).

Hence, from the perspective of the present research, the feminist view of identity, utilized language and power by men advocating or exploiting the female identity, is being considered the idea of patriarchal society. The gender differences are not focused deliberately yet become necessary as the researchers discuss the feminist views related to the statements of the PM and Opponent. Henceforth, this research seeks that how the political language of the elite influences the identity of individuals, especially women, in the present case. For a greater understanding of identity (targeted female identity), collected detailed feminist views (i.e., which they give through their social media accounts, i.e., Twitter) are also added.

In summary, speakers/individuals dominate others (i.e., subordinates) through sociological power, which they often exercise through language (Bourdieu, 1990). Henceforth, in this process, the identity of individuals seems organic and ever-changing (Baxter, 2016; Erikson, 1950). Moreover, meaning-making within the language works when placed within the structure of power (Bourdieu, 1990), so the study argues that individuals make their perspectives via a power source of meaning-making.

\subsection{A Conceptual Framework of the Research}

The researchers have adapted the term Political Discourse Analysis especially from Sibtain et al. (2020) and Iqbal et al. (2020), which they utilized for the study of enthralling features and 
devices that are rhetorical. Furthermore, through them, in the socio-political scenario, they have tried to analyze IK's political speeches. Hence, the PDA model of van Djik (1997b) has been merged by the research with the general Political Discourses analyzed by (Sibtain et al., 2020; Sharif, 2015; Renkema, as cited in Nordquist, 2017). van Dijk (1997b) comments that "without blending political discourse analysis into critical discourse analysis, both aspects of the ambiguous designation would be liked by us to retain: PDA is found in both forms, political discourse form, and a critical enterprise. CDA possesses contemporary approaches in its spirit, and this would mean that critical-political discourse analysis has the potency to deal mainly with the reproducing process of political power, power of abuse, or domination power. Political discourse tends to merge all these aspects mentioned above (p. 11). Fairclough (2012) \& van Dijk (1993b) have described that political discourse analysis deals with the results of political \& social processes where there is no equality and discursive situations that come from such a process of domination (van Dijk, 1997b, p. 11). Additionally, the language that is used in the speeches of political background cannot be perceived only by their literal meanings because often, the politicians use the rhetorical and figurative language that could be conceived only through political and social discourse.

\subsection{Research Gap and Novelty}

The importance of the present study falls in its exceptional investigation and spoken discourse analysis that plays a remarkable role in the applied linguistics' field, particularly concerning Discourse Analysis. Additionally, the study adds different aspects to the area related to Political Discourse Analysis by unfolding the task of political tools in the improvement of spoken discourse inside the settings/contexts that are specific, and it also supports the reader to perceive the ideology related to socio-political field found in the speeches the politicians deliver. Also, the purpose of the study will, in the same way, support the common researchers in scanning the media discourses that are emotionally handled by different characters, on the screen, to get their political interests. So, it also helps the researchers to be ready for more findings to be shown on media discourse by getting advantages of the theoretical frameworks distinctively. Quite now, the stream of inquiry is critical in an excellent way to uncover the hidden motivation of media discourse in spoken form.

The researchers aim to explore the persuasive strategies in IK speeches related to identity distortion (deformation: defaming) in the speech specifically on the said topic related to Bilawal Bhutto Zardari. Furthermore, the researchers tend to analyze the material within the range of discourse analysis(political) by employing van Dijk's Political Discourse model (1997b). Nonetheless, not sufficient work seems to be done on IK speeches concerning Political Identity and persuasion, particularly with the PDA perspective. Furthermore, the researchers use the Aristotelian persuasive strategies in the discourses of IK that shape them more aggressive and purposeful. So, the earlier mentioned issue has not been discussed by researchers, and still, it requires to be settled. Hence, the underlying points were objectively reviewed; The research would disclose the persuasive strategies used by IK in his speeches to get his ideology imposed on the minds of the masses. The researchers would search out how Political Discourse supports the researchers to get exposure of the covert plan through 
political and social context.

\section{Methodology}

The methodological frameworks are adapted and modified from Sheffield (2013), Sibtain et al. (2020), and Iqbal et al. (2020). The present research is descriptive and observational. Hence, observations are not enough to understand a phenomenon, yet, also through shared experiences. So, a qualitative research approach is used to understand the statements of the political elite, for instance, the meaning is not discovered, but rather is constructed, and in this perspective the object-subject forms a relationship which comes together to form meaning. Moreover, subjective statements are also included for clear understanding and interpretations by the researchers. For instance, during the descriptive analysis, the researchers tally their thoughts with the media commentators, political experts, feminist activists specifically for the mentioned 2 speeches.

\subsection{Delimitation of the Study}

The present research is delimited to a specific topic the identity deformation in the context of the word 'Sahiba' relevant to the chairman of Pakistan Peoples Party (a political party in Pakistan) which is used by the Pakistani Prime Minister Imran Khan in his speech. In the research, the researchers give the references/arguments before and after the speech specifically for the clarifications of the contextual occurrence of the events relevant to the said topic.

\section{Data Analysis and Interpretation}

\subsection{Power and Language}

In April 2019, the war of words was held between two heads of the major political parties of the country when PM Imran Khan was criticized for his statement related to Japan and Germany border sharing (see Wasim, 2019 for details). Afterward, Consciously/unconsciously, The PM criticized Bilawal Bhutto Zardari (BBZ), through a single word, in his speech in Wana, saying that "Bilawal Bhutto Sahiba Ki Tarha Parchi Par Ni Aya (Trans. I have not come forward on recommendation like Bilawal Bhutto Sahiba). It is the personal thinking of the researchers that The PM mentions the two symbolic words in his statement 'Sahiba' and 'Parchi' (Trans. 'recommendation' and 'Sahiba').

In this section, the researchers interpret the statement as mentioned earlier relating it to power, for instance, PM utilized his ability to popularize the concept of 'Parchi' (Trans. 'recommendation'), which he often tries to simplify in the past during his struggle. In his struggle, whenever he utilized this concept, he did not get the same results because he did not keep the power that he holds at this stage. For instance, before 30 October 2011, the party of the PM was not much popular, so he did not follow the power to elaborate his political agenda on the national level. However, inopportunely, the PM depowers this community-based idea of 
'Parchi' unitizing the word 'Sahiba' with it. The individuals/speakers give power to their speech through specific words or symbols; for instance, Bourdieu (1991) explores this through the idea of 'habitus' and explains that the words and ideas often work through community-based power, which represents the reality of the community in social settings. Though, this power is often called symbolic power, for instance, the invisible power which can be exercised only with the complicity of those who do not want to know that they are subject to it or even that they exercise it. This power would be transformative to keep an ability to change the vision of the world if it is being controlled and used in a legitimate way of commanding communication (see Bourdieu, 1991 for more details).

\subsection{Politics and Language}

Politics plays an essential role in society to construct ideologies and identities. It remains in a human's mind through which they practice unique ideas to spend their lives. Language gives a way to recognize the position of a person in his or her society. People, specifical politicians, make societies according to their interests so that they would control other's minds. Politicians devote themselves to serve their societies in various fields of life. Hence, politics is considered as the main field of life in which power is practiced. Politician recognizes relevant problems which would be dangerous for society. They provide various solutions for a single question. The economic crisis leads to any society in a dangerous zone. Therefore, politicians utilize language to take part in their society to construct or deconstruct different kinds of ideologies, that is why people believe in them. Through language, politicians act like an actor that is why they want to get to power through language from their people who live in society. The language which is used by politicians influences the people during a political conversation. The rise and the fall of voices in political conversations show an upright impact on the audience, which is presented in a political event.

Politicians utilize language to engage their audience. They select those kinds of words that give them support or fame. Sometimes, they utter taboo types of words to grab their follower's attention. In the Urdu language, the word 'Sahiba' represents females based on gender. For example, three types of gender live in any society, i.e., male, female, and neutral. In a dominant male society, power is often related to the male gender. It is considered that a male dominates a female, so males think that they can make a better plan than women or females. Therefore, the 'Sahiba' word is utilized to represent Bilawal as a female. Women feel inferior to men in any society, when their Prime Minister calls any gendered word like 'Sahiba,' which is usually used for women, in his speech to humiliate other male politicians or public figures.

Imran Khan, Prime Minister of Pakistan, uses the word 'Sahiba' in his speech to humiliate the opposition leader "Bilawal Bhutto Zardari." Hence, such kind of words negatively affects the minds of people living in any society, as well as increases gender discrimination among people. By using the term 'Sahiba' in his speech, Imran Khan very skillfully attracts the attention of his audience towards him and shows his political superiority over his opponent Bilawal Zardari. The reaction of opposition party leader shows their anger on using the humorous or gendered word for their leader on a public forum that shows the Prime 
Minister's victory over them and the success of his policies, as well as, his political authority and held over his subordinates and ordinary people.

\subsection{Power, Language, and Identity}

Hence, from the perspective of the present research, the feminist view of identity, utilized language and power by men advocating or exploiting the female identity, is being considered the idea of patriarchal society. The gender differences are not focused deliberately yet become necessary as the researchers discuss the feminist views related to the statements of the PM and Opponent. Henceforth, this research seeks that how the political language of the elite influences the identity of individuals, especially women, in the present case. For a greater understanding of identity (targeted female identity), collected detailed feminist views (i.e., which they give through their social media accounts, i.e., Twitter) are also added.

In the Urdu language, the word 'Sahiba' is often utilized to give a civil status to any woman. This word is used to give honor to any woman. However, semantically, if this word is used for a man, then it criticizes someone due to the situation, and therefore, it possesses its negative perception as well. In the same perspective, Imran Khan uses this word to criticize the Politician, Bilawal Bhutto. Although Bilawal seems male yet, Imran Khan depicts him as a female in a gender sense. It is happened only due to political issues and conflicts between the two political parties. It is thought that women show less confidence in any kind of stressful situation. Hence, they would do households easily as the duties are assigned to them in every dominant male society. It means that a female would perform their tasks more effectively domestically. Hence, this would be a commanding statue for a female as she would decorate her home more beautiful way than a male. She raises and controls her children more effectively than a male. So, this internal identity of women ever remains with her in her whole life, specifically in any dominant male society. Although, every woman keeps a different kind of abilities through which she decides how she would give support to herself or her family. However, as a woman, she is always bounded to perform household duties. Politics is considered a problematic field of life, so it seems that a good politician might be a male candidate. A male candidate pays his attention to politics in a better way than a female candidate. Because in dominant male society, males remain or proceed with authoritative institutions, and they know about the ups and downs of that specific institution in a better way than females. Their way of thinking remains more reality-oriented than women because they keep great exposure in their universe. They go into the depth of any kind of stressful situation and handle that condition in pure form. Their ideas about politics are considered more accurate than women's, so in the field of politics, men want to defeat their male opponent because their male opponent might be given a tough time in politics. When two opponent politicians want to attract their followers, they gently or keenly play with the linguistic features in this way their followers follow them without thinking anything. They practice language to grab their people, and people remember their words to make themselves happy and to make fun of their opponent. Imran Khan calls 'Sahiba' his opponent to discourage him because women keep less ability to make an insensitive decision condition. Politicians know how to run a country, but a female politician faces 
greater difficulty intake the right decision than a male politician. This word 'Sahiba' is associated with Bilawal that gives a weak identity to Bilawal Bhutto Zardari.

\section{Conclusion}

In summary, speakers/individuals dominate others (i.e., subordinates) through sociological power, which they often exercise through language. Henceforth, in this process, the identity of individuals seems organic and ever-changing. Moreover, meaning-making within the language works when placed within the structure of power, so, the study argues that individuals make their perspectives via a power source of meaning-making.

Language gives power to people, yet sometimes people give the power to the language. For instance, in the present case, the word 'Sahiba' gains power through the language that is utilized by the Prime Minister of Pakistan to defame the identity of the chairman leading opposition party. Therefore, politicians often gain power through language, specifically utilizing the controversial (taboo in the present case) vocabulary. In the end, the language which is used by politicians persuades their follower's minds towards their leaders. Politicians utilize language to catch their follower's attention, and the underlying theme of the politicians remains to get power with the help of their audience. This political war consists of a weapon, and that weapon is considered 'Language.' Imran Khan shows his victory in his political procession on his opponent leader Bilawal Bhutto Zardari.

\subsection{Future Recommendations}

The present study is conducted within a specific topic; the identity deformation in the context of the word 'Sahiba' relevant to the chairman of Pakistan Peoples Party (a political party in Pakistan) which is consciously utilized by the Pakistani Prime Minister Imran Khan in his speech to gain political scoring for the time being. Future researchers would adapt the theoretical and conceptual frameworks from the present study to employ them to speeches of Prime Minister Imran Khan and other contemporary leaders/politicians containing taboo vocabulary.

\section{References}

Aazam, F., Baig, F. Z., Baig, T., Khaliq, S., Azam, A., Shamshad, S., \& Aslam, M. Z. (2019). A Critical Discourse Analysis of 'Fire and Fury: Inside the Trump White House' by Michael Wolff. International Journal of English Linguistics, 9(4), 192-199. https://doi.org/10.5539/ijel.v9n4p192

Akhtar, S., Baig, F. Z. Aslam, M. Z., Khan, T., Tayyaba, S., \& Iqbal, Z. (2020). Code-Switching and Identity: A Sociolinguistic Study of Hanif's Novel Our Lady of Alice Bhatti. International Journal of English Linguistics, 10(1), 363-371. https://doi.org/10.5539/ijel.v10n1p364

Baig, F. Z., Umer, S., Aslam, M. Z., Razaq, M. S., Khan, S., \& Ahmad, Ahmed, T. (2020). Humor as Monotony Breaker in Funny Ads: A Multi-Modal Discourse Analysis of Ads of 
Pakistani Ufone \& Jazz Cellular Companies. International Journal of English Linguistics, 10(1), 69-80. https://doi.org/10.5539/ijel.v10n1p69

Baig, F. Z., Yousaf, W., Aazam, F., Shamshad, S., Fida, I., \& Aslam, M. Z. (2019). Power, Ideology and Identity in Digital Literacy: A Sociolinguistic Study. International Journal of English Linguistics, 9(2), 252-264. https://doi.org/10.5539/ijel.v9n4p252

Baxter. J. (2016). Positioning language and identity from The Routledge Handbook of Language and Identity. London: Routledge.

Bourdieu, P. (1990). In other words: Essays towards a reflexive sociology. Cambridge:

Bourdieu, P. (1991). Language \& symbolic power. Cambridge, MA: Harvard University Press. In Ron Sheffield (2013). The Influence of Language on Culture and Identity: Resurgence of the Quechan Native American Tribal Language (Ph.D. Dissertation). The George Washington University: ProQuest LLC

Creswell, J. (2007). Qualitative inquiry and research design: Choosing among five traditions. Thousand Oaks, CA: Sage Publications, Inc.

Crotty, M. (1998). The foundations of social research: Meaning and perspective in the research process. Allen \& Unwin, St Leonards, NSW.

Dunmire, P. L. (2012), Political Discourse Analysis: Exploring the Language of Politics and the Politics of Language. Language and Linguistics Compass, 6, 735-751. https://doi.org/10.1002/lnc3.365

Erikson, E. (1968). Identity: Youth and crisis. New York, NY: Norton.

Erikson, E. H. (1950). Childhood and society. New York: W. W. Norton.

Erikson, E. H. (1963). Childhood and society. ( $2^{\text {nd }}$ ed.). New York, NY: Norton.

Erikson, E. H., \& Newton, H. P. (1973). In search of common ground. New York, NY: Norton.

Fischer, F., \& Gottweis, H. (eds.). (2012). The argumentative turn revisited: Public policy as communicative practice. Durham, NC; Duke University Press.

Gover, K. (2000). Living water: A cooperative mapping project for Native communities and language revitalization, a native language research initiative (Minneapolis:

Habermas, J. (1981). The theory of communicative action. Vol 1. Reason and the rationalization of society. Boston, MA: Beacon Press.

Hassan, A. (2018). Language, Media, and Ideology: Critical Discourse Analysis of Pakistani News Bulletin Headlines and Its Impact on Viewers. SAGE. https://doi.org/10.1177/2158244018792612

Hatch, M. J., \& Schultz, M. (1997). Relations between organizational culture, identity, and image. European Journal of Marketing, 31(5/6), 356-365. 
Hoare, C. (2012). Three missing dimensions in contemporary studies of identity: The unconscious, negative attributes, and society. Journal of Theoretical and Philosophical Psychology. https://doi.org/10.1037/a0026546

Iqbal, Z., Aslam, M. Z., Aslam, T., Ashraf, R., Kashif, M. \& Nasir, H. (2020). Persuasive Power Concerning COVID-19 Employed by Premier Imran Khan: A Socio-Political Discourse Analysis. Register Journal, 13(1), 208-230. https://doi.org/10.18326/rgt.v13i1.208-230

Kirvalidze, N., \& Samnidize, N. (2016). Political discourse as a Subject of Interdisciplinary Studies. Journal of Teaching and Education, 5(1), 161-170. Retrieved from http://universitypublications.net/jte/0501/pdf/DE5C282.pdf on 3 May 2020

Mead, G. H. (1934). Mind, self, and society. Chicago, IL: University of Chicago Press.

Moustakas, C. (1994). Phenomenological research methods. Thousand Oaks, CA: Sage

Polity Press. In Ron Sheffield (2013). The Influence of Language on Culture and Identity: Resurgence of the Quechan Native American Tribal Language (Ph.D. Dissertation). The George Washington University: ProQuest LLC Publications, Inc.

Ravasi, D., \& Schultz, M. (2006). Responding to organizational identity threats: Exploring the role of organizational culture. Academy of Management Journal, 49(3), 433-458.

Rogers, R., \& Schaenen, I. (2014). Critical Discourse Analysis in Literacy Education: A Review of the Literature. Reading Research Quarterly, 49(1), 121-143. Retrieved 28 April 2020, from www.jstor.org/stable/43497640

Sarfo, E. \& Krampa, A. E (2013). Language at War: A Critical Discourse Analysis of Speeches of Bush and Obama on Terrorism. International J. Soc. Sci. \& Education, 3(2), 378-390. Retrieved from http://ijsse.com/ on 5 May 2020

Schwandt, D. R., \& Marquardt, M. J. (2000). Organizational learning: From world-class theories to global best practices. Boca Raton, FL: St. Lucie Press.

Sharififar, M. \& Rahimi, E. (2015). Critical Discourse Analysis of Political Speeches: A Case Study of Obama's and Rouhani's Speeches at UN. Theory and Practice in Language Studies, 5(2), 343-349. http://dx.doi.org/10.17507/tpls.0502.14

Sheffield, R. (2013). The Influence of Language on Culture and Identity: Resurgence of the Quechan Native American Tribal Language (Ph.D. Dissertation). The George Washington University: ProQuest LLC

Sibtain, M., Aslam, M. Z., ZIA-UR-REHMAN \& Qasim, H. M. (2020). A STUDY OF RHETORICAL ELEMENT AND POLITICAL PERSUASION IN TRUMP'S SPEECH AT UNGA 74TH SESSION: A POLITICAL DISCOURSE ANALYSIS. Hamdard Islamicus: 43(1), 472-486.

Southern California Association of Governments, Winterhaven / Quechan Reservation 
U.S. Census Bureau, 2000 Census of Population and Housing, Characteristics of American Indians and Alaska Natives by Tribe and Language: 2000, PHC-5, Washington, DC, Government Printing Office 2003. U.S. Declaration of Independence (1776).

van Dijk, T. A. (1997b). What is political discourse analysis? In Blommaert, J. \& Bulcaen, C. (eds) Political Linguistics, Amsterdam: Benjamins, 11-52.

van Dijk, T. A. (2000). Ideology: A multidisciplinary approach. London: SAGE Publications Ltd. http://dx.doi.org/10.4135/9781446217856

van Dijk, T. A. (2005). Contextual knowledge management in discourse production. In Wodak, R. \& Chilton, P. A New Agenda in (Critical) Discourse Analysis: Theory, methodology and interdisciplinarity, 13, 71-100. https://doi.org/10.1075/dapsac.13.07dij

van Dijk, T. A. (2006). Discourse and manipulation. Discourse \& Society, 17(3), 359-383. https://doi.org/10.1177/0957926506060250

Vygotsky, L. (1986). Thought and language. Cambridge, MA: The MIT Press.

Wasim, A. (2019, 23 April). 'This is not funny anymore': PM Imran's statement in Iran comes under intense opposition attack. Dawn News. Retrieved from https://www.dawn.com/news/1477903 on 21 May 2020.

Weick, K. E. (1995). Sense-making in organizations (2nd ed.). Thousand Oaks, CA: Sage.

Wodak, R. (2011). The discourse of politics in action: Politics as usual ( $2^{\text {nd }}$ revised edition). London, UK: Palgrave.

Xie, Q. (2018). Critical Discourse Analysis of News Discourse. Theory and Practice in Language Studies, 8(4), 399-403. http://dx.doi.org/10.17507/tpls.0804.06

\section{Copyright Disclaimer}

Copyright for this article is retained by the author(s), with first publication rights granted to the journal.

This is an open-access article distributed under the terms and conditions of the Creative Commons Attribution license (http://creativecommons.org/licenses/by/3.0/). 